\title{
Limitations of Inherent Safety Techniques Application: A Case Study
}

\author{
Maria Aparecida de Paula Lima, Assed Haddad \\ Environmental Engineering, Polytechnic School, Federal University of Rio de Janeiro, Rio de Janeiro, Brazil \\ Email address: \\ mariadepaulalima $a$ gmail.com (M. A. de P. Lima), assed $a$ poli.ufrj.br (A. Haddad)
}

\section{To cite this article:}

Maria Aparecida de Paula Lima, Assed Haddad. Limitations of Inherent Safety Techniques Application: A Case Study. Journal of Energy, Environmental \& Chemical Engineering. Vol. 3, No. 2, 2018, pp. 27-31. doi: 10.11648/j.jeece.20180302.12

Received: March 4, 2018; Accepted: August 22, 2018; Published: September 19, 2018

\begin{abstract}
The present study is motivated by the many accidents in process plants that could be avoided or at least attenuated by inherent safety philosophy. The objective of this article is to understand the real constraints to Inherent Safety Philosophy (ISF) application. It contemplated an evaluation of the limitations and difficulties of applying the inherent safety techniques to process plants based on a specific case study in which some the potential risks to the plant were evaluated and some modifications were advised instead. From this case study, it was possible to extrapolate to a generic case in a representative manner. The greatest difficulties encountered when applying ISF were mapped. The real limitations of using ISF in process plants were related to organizational, technical and economic aspects. The consequently, to focus on finding solutions for them.
\end{abstract}

Keywords: Process Plant, Process Safety, Risk Elimination, Inherent Safety

\section{Introduction}

There are many accidents in process plants that occur every year. It can be observed, however, that many of them could have been avoided had there been some way to prevent them directly in their sources, that is, to eliminate the fact that generated them. Several of these chemical accidents have occurred because of design faults or the overlooking of hazards at an early stage in process design. The Health and Safety Executive examined 34 accidents that were the direct result of control and safety system failures in many different industries. They found that $15 \%$ of accidents were caused by faulty design and implementation.[1] For this reason, the inherent safety often acts to eliminate the risk completely and not only to a level considered acceptable. It would then be obvious the justification for implementing this solution that can be understood as preventive rather than corrective when compared to traditional risk mitigation strategies. This complete elimination of the risk would make any project safer, and this would be the most adequate solution for any engineering project. However, there are several limiting and even impossible factors for the implementation of this safety philosophy. From the theoretical point of view, there is no systematic analytical methodology and there are several configurations that lead to a higher level of inherent safety, which ends up restricting the application. The inherent safety indices are relative ranking methods, achieved by adding parameters without any considerations of the differences in the magnitude of the hazards, the complexity of the procedure, or expert experience and opinion. [2] In addition, the inherent safety is not absolute, it is specific to each plant and place. Therefore, a solution that may be inherently safer for one plant may not be the inherently safer for another plant equal in another location with a different environment. The application of inherent safety requires subjective judgment and compensation between various factors. In addition, the selection and use of inherently safer technology does not by itself guarantee that a plant will result in safer operation between its complex and interrelated systems.

The current economic downturn of oil and gas industry led to more researches dedicated towards the design of processes superior in performance related to their profitability. A process that is economically superior tends to be, in general, safer as well since a safer process has less downtime and thus, more productivity. Nevertheless, there is a tradeoff between the economic and safety 
objectives in the design of a chemical process or its equipment. [3] Safety measures involve both cost-benefit analysis and a decision-making process on whether to invest in a safety measure must account for both aspects. The possible costs of safety measures can be put in many categories. Initially, a proposed safety measure must be selected and the applicable material and training for company personnel must be completed. Afterwards, the installation of the equipment involved may require the plant, or at least part of it, to be shut down resulting in production losses. [4]

Although Inherent Safety applies to the entire productive cycle of a process, plant or material, the greatest opportunities for gaining benefits through the use of Inherent Safety are early in the life cycle - before the technology becomes deeply integrated into the infrastructure of an industry, from raw material suppliers to final product users, and before larger investments in plants and equipment are made. [5]

In this manner, inherent safety plays an important role in the design of safer processes, identifying sustainability based on materials, the handling of critical operation conditions, the operation of large inventories, and the management of process complexity in the process design and plant life cycle.[6]

\section{Inherent Safety Philosophy}

For several decades, the inherent safety was promoted by Dr. Kletz who supports chemical plants that use less hazardous materials in smaller quantities, temperatures and lower pressures. This is said to be inherently or intrinsically safe. The term "inherent" is used in preference to "intrinsic" only because "intrinsically safe" has a technical meaning related to machinery. A plant that is made safer by adding control is extrinsically safe [7].

Rogers and Hallam [8] give an alternative definition of inherently safer: "a process can be considered inherently safer if its design does not produce a hazard if a failure occurs." This is somehow different from the definition of Kletz "Kletz first talks about avoiding danger and, if that is not possible, reducing the size of the hazard as much as possible." Rogers and Hallam talk about making a process that is inherently safe outside normal operation.

There are many examples in daily life of inherent safety or lack of it. The simplest example is the one of Kletz in relation to the use of stairs. Stairs are responsible for more accidents at home than knives or electrical equipment. The way to make the stairs extrinsically safer is by adding handrails, platforms, making the steps shorter or making them less steep. The inherently safest way is to live in a bungalow. In this way, the danger, which is the ladder, is removed.

Inherent safety philosophy is based on four main principles: Intensification, simplification, substitution and moderation [9]. The table 1 summarizes each inherent safety principle.
Table 1. Inherent Safety Principles Summary.

\begin{tabular}{|c|c|}
\hline Feature & Description \\
\hline Intensification & $\begin{array}{l}\text { Use smaller quantities of hazardous substances (also } \\
\text { called minimization) }\end{array}$ \\
\hline Substitution & Replace a material with a less hazardous substance \\
\hline Atenuation & $\begin{array}{l}\text { Use less hazardous conditions, a less hazardous form of a } \\
\text { material or facilities that minimize the impact of a release } \\
\text { of a hazardous material or energy }\end{array}$ \\
\hline Simplification & $\begin{array}{l}\text { Perform projects that eliminate unnecessary complexities } \\
\text { and make operating errors less likely and have some } \\
\text { tolerance for errors. }\end{array}$ \\
\hline
\end{tabular}

Reducing the size of unit operations and chemical plants is a key objective of the process intensification. Process Intensification (PI) results in substantial improvements in scale, cleanliness, energy efficiency, cost-effectiveness and safety of units designed to effect physical changes or molecular transformations in materials. The motivation to intensify processes often comes from the economic side of the business equation. In today's world, the economic need for IP is increasingly shaped within the context of Global Competitiveness and Sustainable Development [10].

In the context of Inherent Safety, "substitution" means the replacement of a hazardous material or process with an alternative that reduces or eliminates the hazard. Process designers, line managers, and the plant's technical staff should continually inquire whether less harmful alternatives can be effectively replaced with all hazardous materials used in a manufacturing process. However, the concept of inherent safety substitution is best applied during the initial design of a process. Substituting raw materials and intermediates after the process has been built, although possible in some cases, is usually very difficult [7].

If intensification and substitution are not feasible, a third path for inherently safer plants is attenuation (or moderation), which involves performing a dangerous reaction under less hazardous conditions or storing or transporting a hazardous material in a less dangerous way.

Simpler plants are safer than more complex ones because they contain less equipment that can leak and provide fewer opportunities for human error. In that sense, they are inherently safer [11].

\section{The Case Study}

The purpose of the process unit assessed at this case study is to perform catalytic dehydrogenation in gas phase of nparaffins in the reactor with downward radial flow. It was assessed considering the four main inherent safety four main principles: intensification, simplification, substitution and moderation.

\subsection{Intensification}

Smaller and more efficient devices such as microreactors and compact heat exchangers should present a lower risk of fire and explosion as well as less damaging emissions than traditional plant equipment. Although large releases and hazards are less likely for intensified plants, the potential for 
operator exposure and minor problems (eg pump leakage) may be greater. This observation is a useful reminder that inherent safety involves both changes that must be managed and trade-offs that should be evaluated [12].

In this case study, a good possibility of reactor intensification is in the substitution of two Alumina Reactors by a single one. The reactors operate in series, and therefore, meet toghether the demand of the plant. This replacement would incur in a reduction in the number of plant equipment so that maintenance costs would be reduced by half with this equipment. In addition, the plant would be inherently safer because there would be a halved reduction of the inventory in reaction.

However, in order to make this reduction feasible, it should be ensured that the new production volume would be sufficient to meet the demands of the plant, this can be achieved by doubling the alumina time in the reactor, causing a single perform the treatment for both. Such a solution, however, implies a delay in the availability of processed alumina which can lead to production decreases. One way of reducing the residence time of the alumina in the reactor is to optimize the mixture which could be obtained through a mixing study in the reactor, especially the way the alumina is introduced therein for carrying out the treatment. Some variables such as backflow currents and the temperature can be modified in order to improve the mixing and hence optimize the process. Such modifications, however, may not be feasible to realize since the reactions themselves have specific conditions in which they must occur. Even the flow of fluids has standard conditions to occur.

Another possibility would be to replace the two reactors with a larger one and operate in order to maintain the demand for treated alumina on time. Such substitution would entail the cost of acquiring the new reactor, which could make the process unfeasible since the economy obtained through maintenance would take a long time to offset the expense of the new equipment. Also, if there is only one equipment there could be an operational discontinuity in case of unavailability of the equipment for any reason such as maintenance or even operational contingencies.

The Higee equipment can reduce residence times in distillation equipment to about one second and can reduce inventories by a factor of 1000 [13]. There is great similarity between the successful applications of this technology in the industry with that of the Oxygen Stripper column in the plant studied, it removes the light and traces of water and decomposes peroxides from the purer NPF from the bottom. This column could then be replaced by a Higee unit. However, Higee technology can reduce the capital cost of distillation equipment, but the economy, compared to the total cost of capital of a project, is small. Project engineers and business managers, including those at ICI, where Higee was invented, remain reluctant to invest in new technologies for a small percentage of cost reduction if there are unforeseen and difficulties that prevent or delay the achievement of project results. According to Ramshaw [13] "The main problem to be overcome is the dubious perception by most plant operators of the reliability of rotary machines. It's necessary to convince skeptics that hazardous process fluids can be kept in the equipment ". These same thoughts were addressed by Green et al. [14]. Major oil and chemical companies spend large sums each year on distillation equipment and the potential benefits to them, in reducing costs and increasing safety, would be great. The main reason for implementing innovations in distillation technology is the demand to remain competitive, minimizing capital expenditures and operating costs by increasing production capacity. Often, activities focus on improving the performance characteristics of vapor-liquid contactors such as dishes and fillings. Higee and other process intensification alternatives for large-scale distillation columns do not figure prominently in the review of the distillation field [15]. The long-term use of these beds using rotating parts for data gain and experience will be critical to the market's acceptance of this technology.

\subsection{Substitution}

Taking into account the properties of the hot oil used by the plant, it's possible to see that the possibility of replacing this oil with another one by adding natural oil-seed triglycerides (for example, soybean oil with antioxidants) will lead to an inherently safer plant. For this replacement, however, an evaluation of an oil having the same operating temperature range as the current one would be necessary since the entire facility is designed to meet the current hot oil operating temperature. Another oil with a different operating temperature could require the replacement of pipes and even equipment, which would make the process more expensive and unfeasible. The chemical compatibility must also be taken into account, for example the corrosive properties of the oils. In addition, some properties such as viscosity could force a higher operating temperature due to the difficulty of pumping oil with high viscosity which can be corrected by reducing the viscosity at elevated temperatures.

For this proposed modification, the difficulties would be more in the motivation to carry out this study by the company of the process and the costs of replacing the existing oil inventory. The modifications therefore are not difficult to implement.

\subsection{Limitation of Effects}

The Oxygen Stripper column is not essential to the unit from a process point of view. When the unit is not integrated into a n-paraffin-producing complex, receiving them from another distant plant, some problems of air contamination may occur with the load during transport. Oxygen from the air can dissolve in the charge of n-paraffins and / or combine in the form of peroxides, which could form a kind of gum in exchange and heat production equipment.

It is believed that through operational care and non-use of n-paraffins from distant plants, it is possible to turn the process inherently safer not using this equipment. The implications of such decision are those mentioned above.

The main limitations of this change are the different 
interests between the Safety, Management and Plant Operation teams. The success of the new operation, without the column, will require more attention from operators to ensure there will be no obstruction of piping. This will impact the operators work and the plant management may be against the modification since it can reduce the availability of the NPF and consequently, generate decrease of production even with an increase in the inherent safety of the process.

\section{Conclusion}

The current main limitations and difficulties of the application of qualitative Inherent Safety techniques observed during this case study were related to three aspects: Economical, Technological and Organizational.

Project engineers and business managers remain reluctant to invest in new technologies for a small percentage of cost reduction, in case of unforeseen challenges and difficulties that prevent or delay the achievement of project results. New technologies, such as the case of Higee equipment, have great difficulty in being well accepted since the reduction in cost of a single equipment might not be significant when compared to the whole project in which it is inserted. The lack of data, tools and operational experiences seem to be the main disincentives for the acceptance of new technologies by companies that end up preferring to invest in techniques of optimization of the technologies already known.

From the economic point of view, the success in the application of Inherent Safety techniques is mainly due to the stage of the project. In the initial stages of product design, conceptual and even basic engineering may be feasible to modify a design taking into account the applications of these techniques, but in the case of a plant already operating as in this case study, the capital costs of engineering and new equipment purchase may limit the application of techniques even if operating costs are reduced. Companies are often not interested in making investments in safety and prefer to invest in projects focused on increasing their yield, production, efficiency and performance because the return of investment for these types of projects are more directly and easily measurable. The gains achieved with inherent safety, such as the elimination of maintenance costs due to non-use of safety instruments, cannot even be estimated since process plants usually do not want to map this type of expense, turning the gains from this type of application are hardly measurable. In addition, other safety techniques with structured, conclusive and conspicuous application methodologies such as risk analysis (HAZOP, LOPA, SIL, etc.) are mandatory for the plant design projects and are usually preferred since the inherent safety techniques do not have application methodologies and may incur in many trade-offs that difficult to understand if one project is inherently safer than another.

Inherent Safety only can solve the problem of whether a project $A$ is inherently safer than a project $B$ with respect to some specific aspects and not of the plant as a whole.

Organizational issues limit the application of inherent
Safety techniques. As organizations are divided into sectors and these sectors are divided into teams that often have conflicting needs and views, some modifications proposed by the applications of the techniques may simply not be implemented because of the hindrance of some of these specific sectors of the companies. Whether it is a matter of ideology in which particular groups may be more or less inclined to adopt less traditional solutions or technical issues in which particular groups may have their work increased, or rather more precisely executed, to ensure tighter operational conditions. Or, for issues related to investor interest, such as if the new conditions proposed by the Inherent Safety techniques can reduce the autonomy and availability of the plant, causing production outages to occur.

Finally, it can be concluded that inherent safety can be more easily applied with the improvement of structured techniques allowing a definitive comparison of the level of safety of different plants possible for the same process.

\section{References}

[1] N. Jang, K. Han, J. Koo, Y. Yoon, J. Yong, and E. S. Yoon, "Development of chemical accident classification codes and tool for management in process industries," J. Chem. Eng. Japan, 2009.

[2] D. Song, E. S. Yoon, and N. Jang, "A framework and method for the assessment of inherent safety to enhance sustainability in conceptual chemical process design," J. Loss Prev. Process Ind., 2018.

[3] N. Ade, G. Liu, A. F. Al-Douri, M. M. El-Halwagi, and M. S. Mannan, "Investigating the effect of inherent safety principles on system reliability in process design," Process Saf. Environ. Prot., vol. 117, pp. 100-110, 2018.

[4] G. Reniers, L. Talarico, and N. Paltrinieri, "Cost-Benefit Analysis of Safety Measures," Dyn. Risk Anal. Chem. Pet. Ind., pp. 195-205, Jan. 2016.

[5] D. Hendershot, "What does inherently safer mean D. Hendershot," CEP Mag., pp. 23-25, 2010.

[6] F. I. Khan and P. R. Amyotte, "How to Make Inherent Safety Practice a Reality," Can. J. Chem. Eng., vol. 81, no. 1, pp. 216, 2003.

[7] T. A. Kletz and P. Amyotte, Process Plants: A Handbook for Inherently Safer Design. 2010.

[8] R. L. Rogers and S. Hallam, "A chemical approach to inherent safety," no. 124, pp. 235-241, 1991.

[9] S. Mannan, "Challenges in implementing inherent safety principles in new and existing chemical processes," Mary Kay O'Connor Process Saf. Cent., 2002.

[10] J. C. Charpentier, "In the Frame of Globalization and Sustainability, Process Intensification, a Path to the Future of Chemical and Process Engineering (Molecules into Money)," Chem. Eng. J., vol. 1-3, no. 134, pp. 84-92, 2007.

[11] CCPS, Inherently Safer Chemical Processes: a Life Cycle Approach, Second. New York, USA: John Wiley \& Sons, Inc and American Institute of Chemical Engineers, 2009. 
[12] P. N. Khoshabi ; Sharratt, "Inherent Safety Through Intensive Structured Processing: the IMPULSE Project," IChemE, no. 153, pp. 1-5, 2007.

[13] C. Ramshaw, “HIGEE' DISTILLATION - AN EXAMPLE OF PROCESS INTENSIFICATION.," Chem. Eng., no. 389, pp. 13-14, 1983.
[14] A. Green, B. Johnson, and A. John, "Process intensification magnifies profits," Chem. Eng., vol. 103, no. 13, pp. 66-73, 1999.

[15] Ž. Olujić, M. Jödecke, A. Shilkin, G. Schuch, and B. Kaibel, "Equipment improvement trends in distillation," Chemical Engineering and Processing: Process Intensification, vol. 48, no. 6. pp. 1089-1104, 2009. 